\title{
Duration of antiresorptive activity of zoledronate in postmenopausal women with osteopenia: a randomized, controlled multidose trial
}

Andrew Grey MD, Mark J. Bolland PhD, Anne Horne MBChB, Borislav Mihov BPhty, Greg Gamble MSc, Ian R. Reid MD

Cite as: CMAJ 2017 September 11;189:E1130-6. doi: 10.1503/cmaj.161207

\begin{abstract}
BACKGROUND: Intravenous zoledronate $5 \mathrm{mg}$ annually reduces fracture risk, and $5 \mathrm{mg}$ every 2 years prevents bone loss, but the optimal dosing regimens for these indications are uncertain.
\end{abstract}

METHODS: We conducted a 3-year open-label extension of a 2-year randomized, placebo-controlled, doubleblind study. Late postmenopausal women with osteopenia were assigned to receive a single baseline dose of $1 \mathrm{mg}, 2.5 \mathrm{mg}$ or $5 \mathrm{mg}$ of zoledronate or placebo. The primary outcome was change in spine bone mineral density (BMD). Secondary outcomes were changes in hip BMD and serum markers of bone turnover.
RESULTS: The study involved 160 women. Zoledronate increased BMD and reduced markers of bone turnover in a dose-dependent manner. After 2 years, the 1-mg, 2.5-mg and 5-mg zoledronate doses increased spine BMD over placebo by $5.0 \%$ (95\% confidence interval $[\mathrm{Cl}]$ $3.0 \%$ to $7.0 \%), 5.7 \%(95 \% \mathrm{Cl} 3.7 \%$ to $7.7 \%$ ) and $5.7 \%(95 \% \mathrm{Cl} 3.7 \%$ to $7.6 \%)$, respectively; after 5 years, the respective increases were $2.0 \%(95 \% \mathrm{Cl}-1.1 \%$ to $5.0 \%), 2.2 \%(95 \% \mathrm{Cl}-1.0 \%$ to $5.4 \%)$ and $5.1 \%$ (95\% Cl $2.2 \%$ to $8.1 \%)$. After 2 years, the 1-mg, 2.5-mg and 5-mg zoledronate doses increased total hip BMD over placebo by $2.6 \%$ (95\% Cl $1.3 \%$ to $3.9 \%)$, $4.1 \%(95 \% \mathrm{Cl} 2.9 \%$ to $5.4 \%)$ and $4.7 \%$ (95\% $\mathrm{Cl} 3.4 \%$ to $5.9 \%$ ), respectively; after
5 years, the respective increases were $1.8 \%$ (95\% Cl $-0.1 \%$ to $3.8 \%$ ), $2.8 \%$ (95\% $\mathrm{Cl} 0.8 \%$ to $4.8 \%)$ and $5.4 \%(95 \% \mathrm{Cl} 3.5 \%$ to $7.3 \%$ ). BMD remained above baseline values for 2-3 years in the 1-mg group, 3-4 years in the $2.5-\mathrm{mg}$ group and at least 5 years in the 5 -mg group.

INTERPRETATION: The antiresorptive activity of single zoledronate doses of 1-5 mg persist for at least 3 years in postmenopausal women with osteopenia. Clinical trials would be justified to evaluate the effects on fracture risk of less frequent or lower doses of zoledronate than are currently recommended. Trial registration: www.anzctr.org.au, no. ACTRN12607000576426
Z oledronate is an intravenously administered bisphosphonate that has been shown in randomized clinical trials to reduce fracture risk in osteoporosis. ${ }^{1,2} \mathrm{~A}$ notable feature of zoledronate is its prolonged activity in bone, such that it is approved for annual administration for treatment of osteoporosis and administration every 2 years for prevention of bone loss. ${ }^{3}$

Despite being in clinical use for almost a decade, the optimal dosing regimen for zoledronate is uncertain. The dose approved for clinical practice, $5 \mathrm{mg}$, is greater than any studied in the phase II zoledronate trial. ${ }^{4}$ That trial, which lasted only 1 year, did not identify the optimal dose and dosing interval for zoledronate. It studied the effects of total zoledronate doses of $1 \mathrm{mg}$, $2 \mathrm{mg}$ and $4 \mathrm{mg}$, administered at intervals including 3 months, 6 months and 12 months. ${ }^{4}$ The zoledronate treatments produced effects on bone mineral density (BMD) and biochemical markers of bone turnover that were superior to placebo, were indistinguishable from one another and remained substantial after 1 year. These effects on surrogate markers for fracture suggest that smaller or less frequent doses of zoledronate than $5 \mathrm{mg}$ annually may also have efficacy in preventing fractures.

Evidence that less frequent administration of the currently recommended 5-mg dose of zoledronate might reduce fracture risk includes data from randomized clinical trials conducted in postmenopausal women, ${ }^{5}$ older women in institutional care ${ }^{6}$ and men with HIV infection, ${ }^{7}$ which have indicated that 4-mg and 5-mg doses of zoledronate produce antiresorptive activity that persists for up to 5 years. A post hoc analysis of the zoledronate phase III trials reported similar reductions in fracture risk after 3 years in response to 3 annual administrations of $5 \mathrm{mg}$ zoledronate and a single baseline administration of $5 \mathrm{mg} .{ }^{8}$ 
At present, there are no long-term data on the duration of antiresorptive activity of zoledronate at doses below $4 \mathrm{mg}$. In a 2-year randomized placebo-controlled trial of single baseline doses of zoledronate ( $1 \mathrm{mg}, 2.5 \mathrm{mg}$ or $5 \mathrm{mg}$ ) in 180 postmenopausal women with mild bone loss, we reported substantial and sustained effects of each zoledronate dose on BMD and bone turnover markers. ${ }^{9,10}$ To clarify the duration of action of each of these doses on these surrogate markers of bone health, we conducted a 3-year open-label extension of the core trial, without further drug administration.

\section{Methods}

\section{Study design and participants}

This trial was an open-label extension of a 2-year double-blind randomized placebo-controlled trial (trial registration ACTRN12607000576426; date of registration Nov. 9, 2007), the design and results of which have been published..$^{9,10}$ In the core trial, 180 late postmenopausal women with mild bone loss (BMD T score between -1 and -2.5 at either lumbar spine or total hip) were randomly assigned to receive a single baseline administration of zoledronate $1 \mathrm{mg}$, zoledronate $2.5 \mathrm{mg}$, zoledronate $5 \mathrm{mg}$ (each given as a 15 -min intravenous infusion in $100 \mathrm{~mL} 0.9 \%$ sodium chloride $[\mathrm{NaCl}])$ or placebo $(100 \mathrm{~mL} 0.9 \% \mathrm{NaCl}$ administered in an identical fashion). Women receiving antiresorptive therapies or systemic glucocorticoids were ineligible, as were those with previous hip fracture, clinical vertebral fracture or postmenopausal wrist fracture; those who had ever used an aminobisphosphonate or had used etidronate within the past 3 years; those with any major systemic illness; and those with serum 25-hydroxyvitamin D below $25 \mathrm{nmol} / \mathrm{L}$. Participants were recruited between January 2008 and July 2009, by advertisements seeking healthy postmenopausal women to participate in clinical bone research and by approaching participants who had previously been involved in clinical research within our group and had indicated interest in participating in future studies. The study was configured to detect a difference $(2$-tailed $p<0.05)$ in the change in lumbar spine BMD of $5 \%$ between each of the 3 doses of zoledronate and placebo.

All participants who completed the original protocol $(n=160)$ were eligible for the extension protocol.

\section{Randomization and masking}

Randomization was supervised by the study statistician (G.G.), using a variable block-size schedule based on computer-

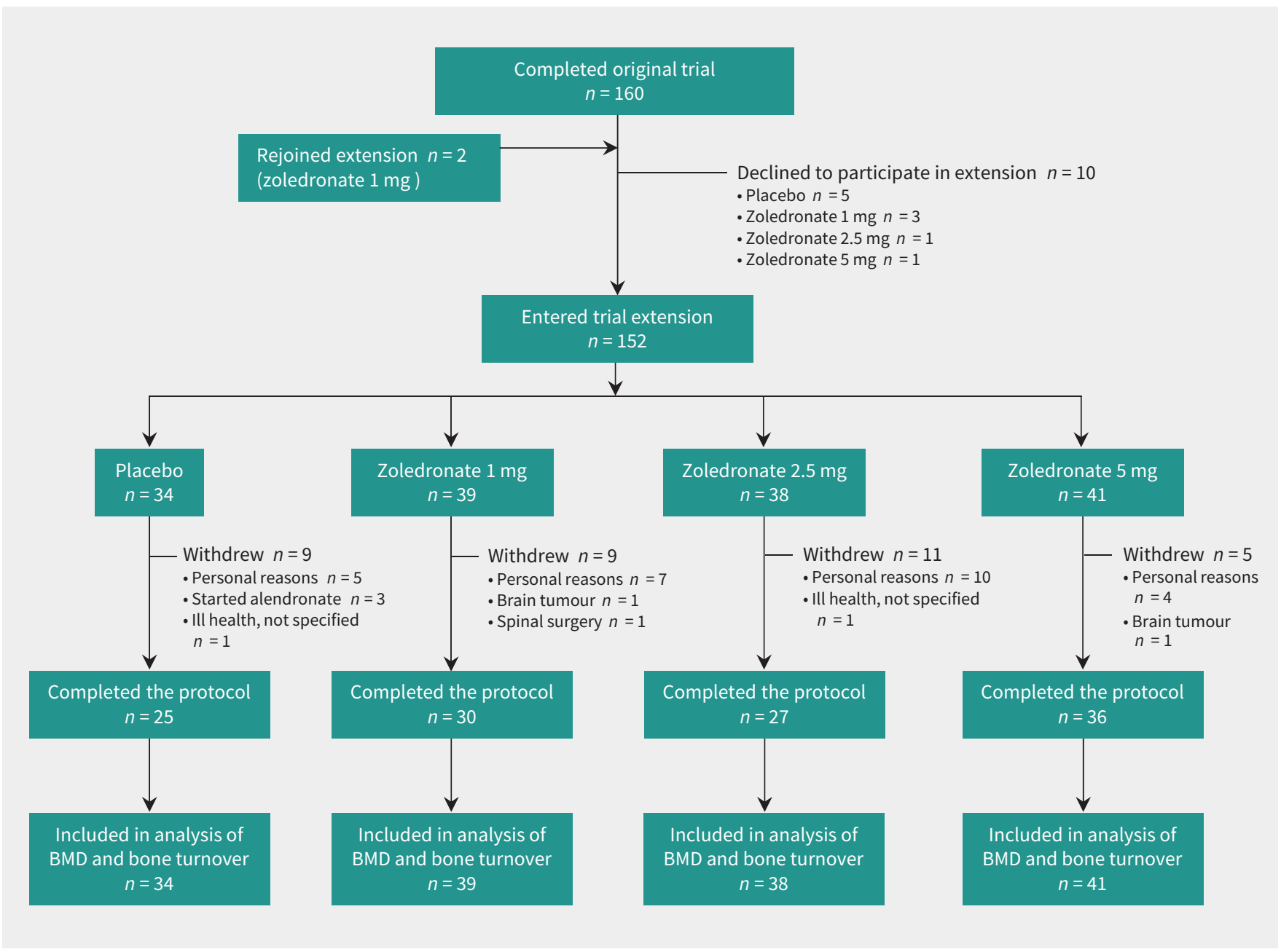

Figure 1: Flow of participants through the trial. $\mathrm{BMD}=$ bone mineral density. 
generated (Microsoft Excel 2003) random numbers. In the core trial, only the statistician and the staff member who prepared the infusions had access to treatment allocation, and neither had contact with participants. Participants were unblinded to treatment allocation after completion of the core trial.

\section{Intervention}

No additional study medication was administered during the trial extension.

\section{Outcome measures}

BMD was measured at lumbar spine (L1-L4), dual total hip and total body at 6 monthly intervals in the core trial, and then at 30, 36, 42, 48 and 60 months in the extension trial. Densitometry was performed with a Lunar Prodigy dual-energy x-ray absorptiometer (GE Lunar). The coefficients of variation for measurement of total hip and lumbar spine BMD in our laboratory are $1.1 \%$ and $1.4 \%$, respectively.

The serum markers of bone resorption (B-C-terminal telopeptide of type I collagen [B-CTX]) and bone formation (procollagen type $1 \mathrm{~N}$-terminal propeptide [P1NP]) were measured in samples collected after overnight fasting at baseline; at 3, 6, 9, 12, 18 and 24 months in the core trial; and then at 30, 36, 42, 48 and 60 months in the extension protocol. Measurements were performed using the Elecsys 2010 platform (Roche Diagnostics). The coefficients of variation for these markers are $5.1 \%$ for B-CTX and $1.9 \%$ for P1NP.

\section{End points}

The primary end point of the core trial was change in lumbar spine BMD. Secondary end points were change in BMD at total hip and total body, and changes in B-CTX and P1NP. The same hierarchy of end points was applied to the extension protocol.

\section{Statistical analysis}

The primary analysis was by intention to treat and was undertaken for all participants who were randomly assigned in the core trial and who consented to participate in the extension protocol. A secondary analysis was performed with data for only those participants who completed the 5-year protocol. We analyzed the data using a mixed-models analysis of covariance approach to repeated measures (unstructured covariance) with the absolute change in BMD or bone turnover marker as the dependent variable and including baseline level of the dependent variable as the covariable. Significant time by treatment interaction effects were further explored by post hoc comparison of each dose with placebo at each time point (Dunnett test). Values of $p$ less than 0.05 were considered statistically significant, and all tests were 2-tailed. We used SAS version 9.4 (SAS Institute Inc.) for all analyses.

\section{Ethics approval}

The extension protocol received ethics approval from the Northern Y Regional Ethics Committee. All participants gave written, informed consent.

Table 1: Baseline data for trial participants

\begin{tabular}{|c|c|c|c|c|}
\hline \multirow[b]{2}{*}{ Characteristic } & \multicolumn{4}{|c|}{ Placebo or zolendronate dose; mean $\pm \mathrm{SD}^{\star}$} \\
\hline & $\begin{array}{c}\text { Placebo } \\
n=34\end{array}$ & $\begin{array}{c}1 \mathrm{mg} \\
n=39\end{array}$ & $\begin{array}{c}2.5 \mathrm{mg} \\
n=38\end{array}$ & $\begin{array}{c}5 \mathrm{mg} \\
n=41\end{array}$ \\
\hline Age, yr & $63 \pm 8$ & $64 \pm 8$ & $67 \pm 9$ & $66 \pm 8$ \\
\hline Weight, kg & $67 \pm 13$ & $68 \pm 9$ & $66 \pm 10$ & $66 \pm 12$ \\
\hline Current smoker, no. (\%) & 0 & 0 & $1(3)$ & 0 \\
\hline Calcium intake, $\mathrm{mg} / \mathrm{d}$ & $956 \pm 327$ & $965 \pm 336$ & $881 \pm 411$ & $852 \pm 522$ \\
\hline Serum 25-hydroxyvitamin D, nmol/L & $74 \pm 19$ & $71 \pm 17$ & $67 \pm 19$ & $71 \pm 20$ \\
\hline Fracture during adulthood, no. $(\%) \dagger$ & $8(24)$ & $18(46)$ & $8(21)$ & $12(29)$ \\
\hline Lumbar spine BMD, $\mathrm{g} / \mathrm{cm}^{2}$ & $1.02 \pm 0.10$ & $1.02 \pm 0.08$ & $1.03 \pm 0.11$ & $1.05 \pm 0.12$ \\
\hline T score & $-1.4 \pm 0.8$ & $-1.3 \pm 0.7$ & $-1.2 \pm 0.9$ & $-1.1 \pm 1.0$ \\
\hline Total hip BMD, $\mathrm{g} / \mathrm{cm}^{2}$ & $0.87 \pm 0.07$ & $0.85 \pm 0.08$ & $0.84 \pm 0.06$ & $0.84 \pm 0.09$ \\
\hline Tscore & $-1.1 \pm 0.6$ & $-1.2 \pm 0.7$ & $-1.3 \pm 0.5$ & $-1.3 \pm 0.7$ \\
\hline Total body BMD, $\mathrm{g} / \mathrm{cm}^{2}$ & $1.08 \pm 0.06$ & $1.06 \pm 0.06$ & $1.07 \pm 0.06$ & $1.06 \pm 0.05$ \\
\hline T score & $-0.6 \pm 0.7$ & $-0.8 \pm 0.7$ & $-0.7 \pm 0.8$ & $-0.8 \pm 0.7$ \\
\hline P1NP, $\mu \mathrm{g} / \mathrm{L}$ & $55 \pm 23$ & $61 \pm 21$ & $57 \pm 16$ & $58 \pm 18$ \\
\hline$\beta-C T X, n g / L$ & $460 \pm 210$ & $470 \pm 200$ & $480 \pm 180$ & $460 \pm 220$ \\
\hline
\end{tabular}




\section{Results}

During the initial recruitment period, 613 women received study information after responding to advertisements, as did 12 participants in previous studies who had indicated interest in participating in future studies. The flow of participants through the core trial and extension is shown in Figure 1. Table 1 contains the baseline data for trial participants. The participants who entered the extension were similar to the cohort of participants who enrolled in the core trial (Appendix 1, available at www.cmaj.ca/ lookup/suppl/doi:10.1503/cmaj.161207/-/DC1). ${ }^{9}$ Three participants, all in the placebo group, commenced alendronate therapy. One participant in the group that received zoledronate $2.5 \mathrm{mg}$ also received prednisone for giant cell arteritis for 23 months at an average dose of $10 \mathrm{mg} /$ day. No participants died during the trial. The number of participants contributing data at each annual time point is shown in Appendix 2 (available at www.cmaj.ca/lookup/suppl/doi:10.1503/cmaj.161207/-/DC1).

\section{Bone mineral density}

BMD data are depicted in Figure 2 and, for clarity, the treatment effects of each dose compared with placebo at each annual time point are shown in Table 2. Each dose of zoledronate produced improvements in BMD at each site, compared with placebo. As expected, treatment effects were greatest at the spine, which is enriched for trabecular bone, and least at the total body, which is predominantly cortical bone. In the axial skeleton, statistically significant increases in BMD compared with placebo were observed for the 1-mg, 2.5-mg and 5-mg doses for 3-4 years, 4-5 years and at least 5 years, respectively. Each zoledronate dose produced its largest effect on BMD at 2 years. For the 1-mg dose, the mean increases (95\% confidence interval $[\mathrm{Cl}])$ in spine and hip BMD were $5.0 \%$ (95\% $\mathrm{Cl} 3.0 \%$ to $7.0 \%)$ and $2.6 \%$ (95\% Cl $1.3 \%$ to $3.9 \%$ ), respectively; for the $2.5-\mathrm{mg}$ dose, they were $5.7 \%(95 \% \mathrm{Cl} 3.7 \%$ to $7.7 \%)$ and $4.1 \%(95 \% \mathrm{Cl}$ $2.9 \%$ to $5.4 \%$ ), respectively; and for the $5-\mathrm{mg}$ dose, they were $5.7 \%(95 \% \mathrm{Cl} 3.7 \%$ to $7.6 \%)$ and $4.7 \%(95 \% \mathrm{Cl} 3.4 \%$ to $5.9 \%)$, respectively.

Offset of zoledronate effects was dose-dependent and slow. For the 1-mg dose, the differences in BMD compared with placebo decreased after 2 years; for the 2.5-mg dose, the differences in BMD compared with placebo decreased after 2-3 years; and for the 5-mg dose, the differences in BMD compared with placebo remained stable until 5 years. After 5 years, the increases in spine and hip BMD compared with placebo for the 1-mg dose were $2.0 \%(95 \% \mathrm{Cl}-1.1 \%$ to $5.0 \%)$ and $1.8 \%(95 \% \mathrm{Cl}-0.1 \%$ to $3.8 \%)$, respectively; for the $2.5-\mathrm{mg}$ dose, they were $2.2 \%(95 \% \mathrm{Cl}$ $-1.0 \%$ to $5.4 \%$ ) and $2.8 \%$ (95\% $\mathrm{Cl} 0.8 \%$ to $4.8 \%)$, respectively; and for the $5-\mathrm{mg}$ dose, they were $5.1 \%(95 \% \mathrm{Cl} 2.2 \%$ to $8.1 \%)$ and $5.4 \%(95 \% \mathrm{Cl} 3.5 \%$ to $7.3 \%)$, respectively.

Spine BMD returned to baseline level 5 years after administration of both the 1-mg and 2.5-mg doses, but remained above baseline in the group that received the 5-mg dose. Hip BMD returned to baseline level 2.5 years after administration of the 1-mg dose and 4.5 years after administration of the 2.5-mg dose, and remained above baseline levels 5 years after administration
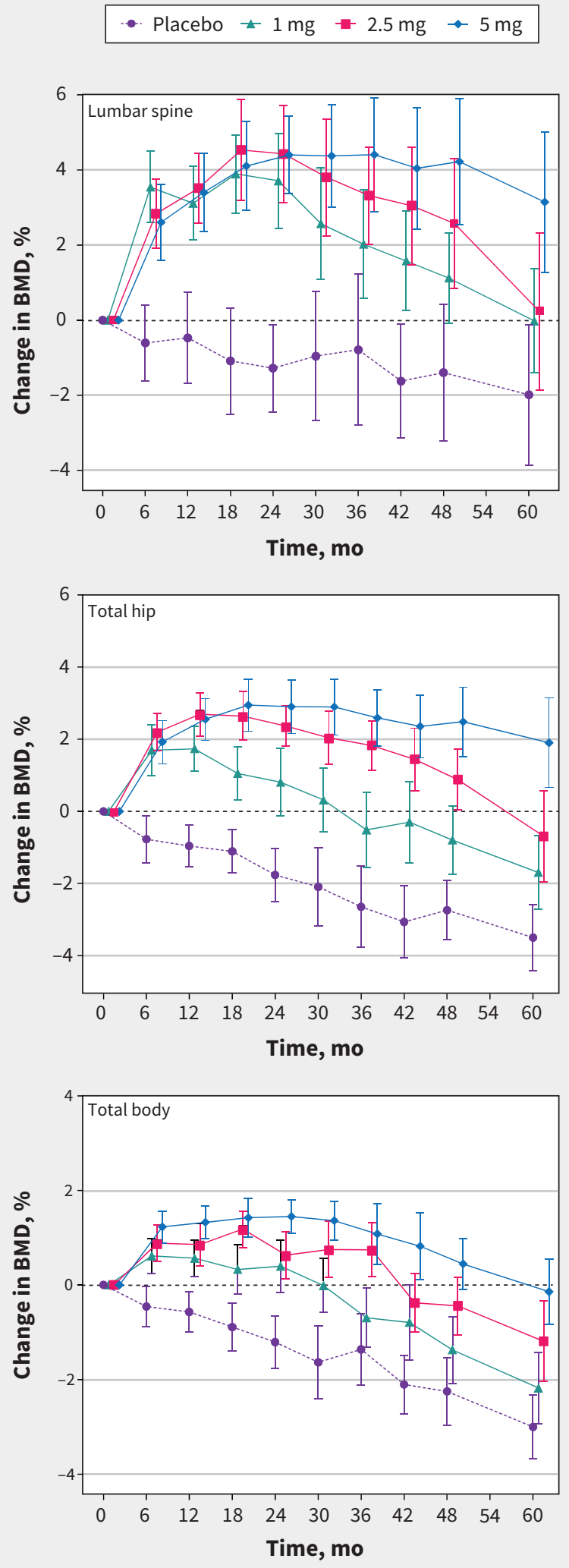

Figure 2: Effects of study treatments on bone mineral density (BMD) of the lumbar spine (top), total hip (middle) and total body (bottom) over 5 years in postmenopausal women with osteopenia. Treatment doses refer to zoledronate. Data are mean percent changes from baseline (95\% confidence intervals). 
of the 5-mg dose. The 1-mg, 2.5-mg and 5-mg doses of zoledronate maintained total body BMD at or above baseline values for 2.5 years, 3.5 years and 5 years, respectively.

In the secondary analysis including only participants who completed the 5-year protocol, the results were similar (data not shown).

\section{Bone turnover markers}

Data for bone turnover markers are shown in Figure 3, and annual percentage changes compared with placebo for each zoledronate dose are recorded in Table 2. Each dose of zoledronate substantially reduced bone turnover markers soon after administration, after which each marker of bone turnover slowly increased toward values in the placebo group. The mean level of the bone resorption marker, B-CTX, was within $20 \%$ of that in the placebo group in the 1 -mg zoledronate group by 24 months, and in the $2.5-\mathrm{mg}$ zoledronate group by 60 months; in the 5-mg zoledronate group, the value was $27 \%$ lower than placebo at 60 months. Changes in P1NP showed similar patterns.

\section{Fractures}

Incident fractures were infrequent and similar among treatment groups ( $p=0.9)$. In the placebo group, 4 participants experienced 4 fractures (1 humerus, 1 rib, 2 foot); in the 1-mg zoledronate group, 3 participants experienced 3 fractures (1 rib, 1 humerus, 1 foot); in the 2.5-mg zoledronate group, 3 participants experienced 3 fractures ( 1 toe, 1 forearm, 1 finger); and in the 5-mg zoledronate group, 4 participants experienced 5 fractures ( 1 toe, 1 finger, 1 hand, 1 forearm, 1 knee).

\section{Interpretation}

This extension of a randomized controlled trial provides confirmatory and novel information about the duration of the antiresorptive activity of single intravenous doses of $1 \mathrm{mg}, 2.5 \mathrm{mg}$ and $5 \mathrm{mg}$ of zoledronate. It confirms our earlier report ${ }^{7}$ that a single 5-mg dose of zoledronate increases BMD above baseline levels and reduces bone turnover markers below baseline levels for at least 5 years. In addition, it suggests that 1-mg and 2.5-mg doses of zoledronate also have long durations of action, such that a 1-mg dose prevents bone loss for 30 months and a 2.5-mg dose for at least 42 months. These data clearly show that the offset of antiresorptive action of zoledronate is gradual, occurring over several years.

Our results raise questions about current recommendations that annual administration of $5 \mathrm{mg}$ zoledronate be used to treat osteoporosis ${ }^{1,2}$ and that $5 \mathrm{mg}$ be administered every 2 years to prevent bone loss. ${ }^{3}$ The current data show that a 1-mg dose of zoledronate prevents bone loss for 2-3 years, a 2.5-mg dose prevents bone loss for 3-4 years, and a 5-mg dose prevents bone loss for at least 5 years. Thus, doses of zoledronate both smaller and less frequent than the currently recommended $5 \mathrm{mg}$ dose every 2 years can be administered to prevent bone loss.

These results also suggest that reduction in fracture risk may be achieved using 1-mg to 5-mg doses of zoledronate less frequently than annually. A single dose of $1 \mathrm{mg}, 2.5 \mathrm{mg}$ or $5 \mathrm{mg}$ zoledronate produced sustained suppression of bone turnover and significantly increased BMD compared with placebo for about 2 years, 4 years and 5 years, respectively. Sustained changes of similar magnitude in bone turnover markers and BMD have been

Table 2: Annual changes in BMD and bone turnover markers during 5 years after a single administration of zoledronate

\begin{tabular}{|c|c|c|c|c|c|c|c|c|c|c|c|c|}
\hline $\begin{array}{l}\text { Time } \\
\text { (mo) }\end{array}$ & \multicolumn{12}{|c|}{ Zolendronate dose; mean \% difference from placebo $(95 \% \mathrm{Cl})^{\star}$} \\
\hline 12 & $\begin{array}{c}3.6 \\
(1.8 \text { to } \\
5.3)\end{array}$ & $\begin{array}{c}2.7 \\
(1.7 \text { to } \\
3.7)\end{array}$ & $\begin{array}{c}-45 \\
(-56 \text { to } \\
-34)\end{array}$ & $\begin{array}{c}-44 \\
(-57 \text { to } \\
-30)\end{array}$ & $\begin{array}{c}4.0 \\
(2.2 \text { to } \\
5.8)\end{array}$ & $\begin{array}{c}3.7 \\
\text { (2.6 to } \\
4.7)\end{array}$ & $\begin{array}{c}-69 \\
(-81 \text { to } \\
-57)\end{array}$ & $\begin{array}{c}-60 \\
(-74 \text { to } \\
-46)\end{array}$ & $\begin{array}{c}3.9 \\
\text { (2.1 to } \\
5.6)\end{array}$ & $\begin{array}{c}3.5 \\
(2.5 \text { to } \\
4.5)\end{array}$ & $\begin{array}{c}-74 \\
\text { (-85 to } \\
-63)\end{array}$ & $\begin{array}{c}-66 \\
(-80 \text { to } \\
-52)\end{array}$ \\
\hline 24 & $\begin{array}{c}5.0 \\
(3.0 \text { to } \\
7.0)\end{array}$ & $\begin{array}{c}2.6 \\
(1.3 \text { to } \\
3.9)\end{array}$ & $\begin{array}{c}-20 \\
(-34 \text { to } \\
-6)\end{array}$ & $\begin{array}{c}-19 \\
(-33 \text { to } \\
-5)\end{array}$ & $\begin{array}{c}5.7 \\
\text { (3.7 to } \\
7.7)\end{array}$ & $\begin{array}{c}4.1 \\
\text { (2.9 to } \\
5.4)\end{array}$ & $\begin{array}{c}-47 \\
(-61 \text { to } \\
-34)\end{array}$ & $\begin{array}{c}-32 \\
(-45 \text { to } \\
-19)\end{array}$ & $\begin{array}{c}5.7 \\
\text { (3.7 to } \\
7.6)\end{array}$ & $\begin{array}{c}4.7 \\
\text { (3.4 to } \\
5.9)\end{array}$ & $\begin{array}{c}-53 \\
(-66 \text { to } \\
-40)\end{array}$ & $\begin{array}{c}-31 \\
(-44 \text { to } \\
-19)\end{array}$ \\
\hline 36 & $\begin{array}{c}2.8 \\
(0.1 \text { to } \\
5.5)\end{array}$ & $\begin{array}{c}2.1 \\
(0.6 \text { to } \\
3.7)\end{array}$ & $\begin{array}{c}-7 \\
\text { (-30 to } \\
15)\end{array}$ & $\begin{array}{c}-23 \\
(-50 \text { to } \\
5)\end{array}$ & $\begin{array}{c}4.1 \\
\text { (1.4 to } \\
6.8)\end{array}$ & $\begin{array}{c}4.5 \\
(2.9 \text { to } \\
6.1)\end{array}$ & $\begin{array}{c}-38 \\
(-61 \text { to } \\
-15)\end{array}$ & $\begin{array}{c}-38 \\
\text { (-66 to } \\
-11)\end{array}$ & $\begin{array}{c}5.2 \\
(2.5 \text { to } \\
7.9)\end{array}$ & $\begin{array}{c}5.2 \\
\text { (3.7 to } \\
6.8)\end{array}$ & $\begin{array}{c}-42 \\
(-65 \text { to } \\
-19)\end{array}$ & $\begin{array}{c}-30 \\
(-58 \text { to } \\
-3)\end{array}$ \\
\hline 60 & $\begin{array}{c}2.0 \\
(-1.1 \text { to } \\
5.0)\end{array}$ & $\begin{array}{c}1.8 \\
(-0.1 \text { to } \\
3.8)\end{array}$ & $\begin{array}{c}-2 \\
(-25 \text { to } \\
21)\end{array}$ & $\begin{array}{c}-6 \\
(-26 \text { to } \\
14)\end{array}$ & $\begin{array}{c}2.2 \\
(-1.0 \text { to } \\
5.4)\end{array}$ & $\begin{array}{c}2.8 \\
(0.8 \text { to } \\
4.8)\end{array}$ & $\begin{array}{c}-19 \\
(-43 \text { to } \\
5)\end{array}$ & $\begin{array}{c}-10 \\
(-31 \text { to } \\
10)\end{array}$ & $\begin{array}{c}5.1 \\
(2.2 \text { to } \\
8.1)\end{array}$ & $\begin{array}{c}5.4 \\
(3.5 \text { to } \\
7.3)\end{array}$ & $\begin{array}{c}-27 \\
(-49 \text { to } \\
-4)\end{array}$ & $\begin{array}{c}-22 \\
(-41 \text { to } \\
-3)\end{array}$ \\
\hline
\end{tabular}



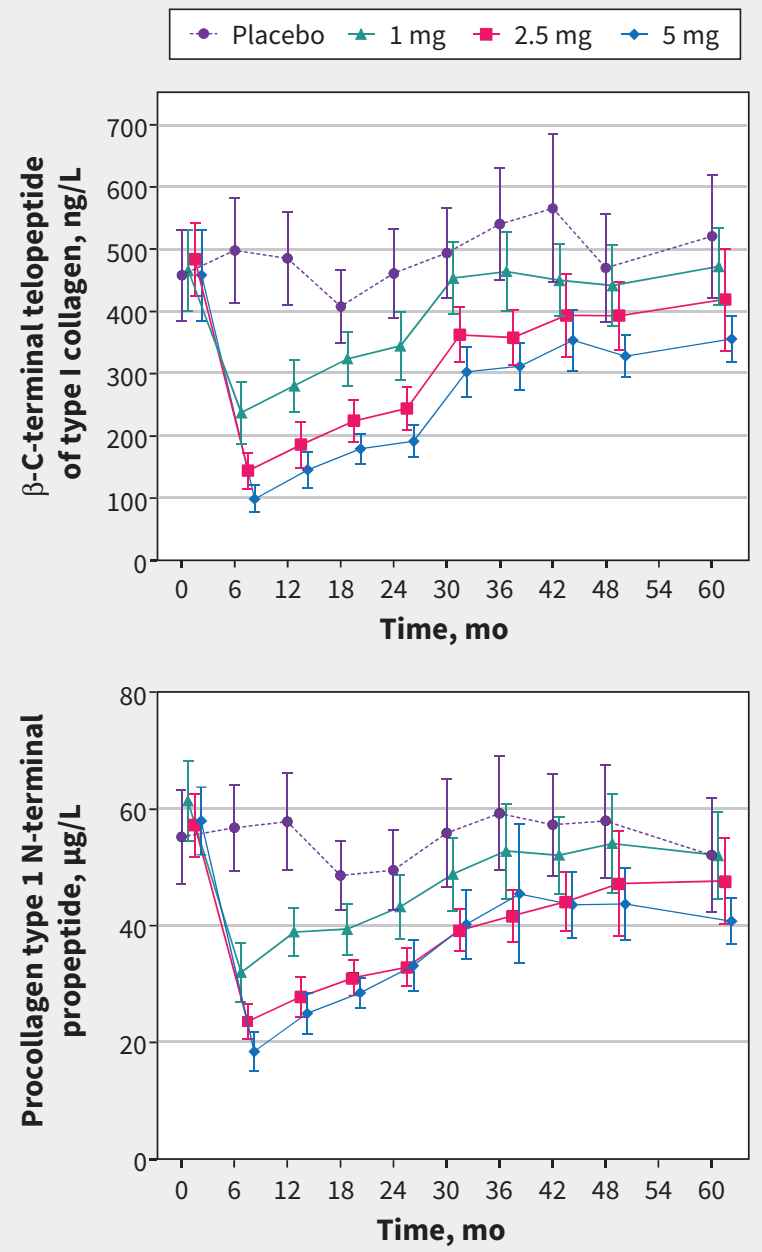

Figure 3: Effects of study treatments on markers of bone turnover, specifically $\beta$-C-terminal telopeptide of type I collagen (top) and procollagen type $1 \mathrm{~N}$-terminal propeptide (bottom), over 5 years in postmenopausal women with osteopenia. Treatment doses refer to zoledronate. Data are means ( $95 \%$ confidence intervals).

associated with fracture risk reduction for other bisphosphonates. ${ }^{11,12}$ Furthermore, this hypothesis is supported by post hoc analysis of the zoledronate phase III trial program that reported equivalent relative risk reduction for all clinical fractures at 3 years for participants who received 3 annual 5 -mg doses (34\%) and those who received only a single baseline 5 -mg dose $(32 \%){ }^{8}$ A small 2-year trial of a single 5-mg zoledronate dose given to frail older women living in institutional settings, which found no reduction in incident fractures despite the expected changes in BMD, was not powered for fracture end points. ${ }^{6}$ Another bisphosphonate, risedronate, may reduce fracture risk at lower doses than are recommended in clinical practice..$^{13}$

These results are clinically relevant. The slow offset of action of zoledronate contrasts with the quicker offset of therapies such as denosumab ${ }^{14}$ and parathyroid hormone. ${ }^{15,16}$ In general, medium- and long-term adherence to treatments to reduce frac- ture risk is low, and low adherence is associated with higher fracture incidence. ${ }^{17}$ In this context, the availability of a medication with prolonged activity and slow offset might help to mitigate some of the adverse effects of low rates of treatment adherence. The efficacy of lower doses suggests that they may be preferable when drug toxicity is a concern, as for recipients with impaired renal function.

\section{Limitations}

Our study had limitations. Participants were at low fracture risk, so the results may not apply to those with established osteoporosis. Although participants were randomly assigned to treatments and the end points were measured objectively, the extension protocol was open-label. Our trial was originally powered to compare each dose of zoledronate with placebo, so it does not permit conclusions to be drawn about the relative effects of the different doses of zoledronate. Finally, an important limitation is that the end points of BMD and bone turnover markers are surrogates for bone fragility.

\section{Conclusion}

The current study found prolonged antiresorptive activities of single zoledronate doses of 1 to $5 \mathrm{mg}$ in postmenopausal women with osteopenia. Conducting clinical trials to evaluate the effects on fracture risk of less frequent or lower doses of zoledronate than are currently recommended is justified, because the results would have important implications for patient care and costs of osteoporosis treatment.

\section{References}

1. Black DM, Delmas PD, Eastell R, et al.; HORIZON Pivotal Fracture Trial. Onceyearly zoledronic acid for treatment of postmenopausal osteoporosis. N Engl J Med 2007;356:1809-22.

2. Lyles KW, Colón-Emeric CS, Magaziner JS, et al.; HORIZON Pivotal Fracture Trial. Zoledronic acid and clinical fractures and mortality after hip fracture. N Engl J Med 2007;357:1799-809.

3. McClung M, Miller P, Recknor $\mathrm{C}$, et al. Zoledronic acid for the prevention of bone loss in postmenopausal women with low bone mass: a randomized controlled trial. Obstet Gynecol 2009;114:999-1007.

4. Reid IR, Brown JP, Burckhardt P, et al. Intravenous zoledronic acid in postmenopausal women with low bone mineral density. N Engl J Med 2002;346: 653-61.

5. Grey A, Bolland MJ, Horne A, et al. Five years of anti-resorptive activity after a single dose of zoledronate - results from a randomized double-blind placebocontrolled trial. Bone 2012;50:1389-93.

6. Greenspan SL, Perera S, Ferchak MA, et al. Efficacy and safety of single-dose zoledronic acid for osteoporosis in frail elderly women: a randomized clinical trial. JAMA Intern Med 2015;175:913-21.

7. Bolland MJ, Grey A, Horne AM, et al. Effects of intravenous zoledronate on bone turnover and bone density persist for at least five years in HIV-infected men. J Clin Endocrinol Metab 2012;97:1922-8.

8. Reid IR, Black D, Eastell R, et al.; HORIZON Pivotal Fracture Trial and HORIZON Recurrent Fracture Trial Steering Committees. Reduction in the risk of clinical fractures after a single dose of zoledronic acid $5 \mathrm{mg}$. J Clin Endocrinol Metab 2013;98:557-63.

9. Grey A, Bolland M, Wong S, et al. Low-dose zoledronate in osteopenic postmenopausal women: a randomized controlled trial. J Clin Endocrinol Metab 2012;97:286-92. 
10. Grey A, Bolland M, Mihov B, et al. Duration of antiresorptive effects of low-dose zoledronate in osteopenic postmenopausal women: a randomized, placebocontrolled trial. J Bone Miner Res 2014;29:166-72.

11. Harris ST, Watts NB, Genant HK, et al. Effects of risedronate treatment on vertebral and nonvertebral fractures in women with postmenopausal osteoporosis: a randomized controlled trial. Vertebral Efficacy with Risedronate Therapy (VERT) Study Group. JAMA 1999;282:1344-52.

12. Bauer DC, Black DM, Garnero P, et al.; Fracture Intervention Trial Study Group. Change in bone turnover and hip, non-spine, and vertebral fracture in alendronatetreated women: the fracture intervention trial. J Bone Miner Res 2004;19:1250-8.

13. McClung MR, Geusens P, Miller PD, et al.; Hip Intervention Program Study Group. Effect of risedronate on the risk of hip fracture in elderly women. N Engl J Med 2001;344:333-40.
14. Bone HG, Bolognese MA, Yuen CK, et al. Effects of denosumab treatment and discontinuation on bone mineral density and bone turnover markers in postmenopausal women with low bone mass. J Clin Endocrinol Metab 2011;96: 972-80.

15. Eastell R, Nickelsen T, Marin F, et al. Sequential treatment of severe postmenopausal osteoporosis after teriparatide: final results of the randomized, controlled European Study of Forsteo (EUROFORS). J Bone Miner Res 2009;24: 726-36.

16. Black DM, Bilezikian JP, Ensrud KE, et al.; PaTH Study Investigators. One year of alendronate after one year of parathyroid hormone (1-84) for osteoporosis. N Engl J Med 2005;353:555-65.

17. Compston JE, Seeman E. Compliance with osteoporosis therapy is the weakest link [published erratum in Lancet 2007;369:826]. Lancet 2006;368:973-4.
Competing interests: Andrew Grey is a shareholder in Auckland Bone Density, which provides bone density measurement services. Ian Reid has received research funding and honoraria from Novartis, Merck and Amgen. No other competing interests were declared.

This article has been peer reviewed.

Affiliation: Department of Medicine, University of Auckland, Auckland, New Zealand

Contributors: Andrew Grey, Mark Bolland, Anne Horne, Greg Gamble and lan Reid contributed to study design. Anne Horne and Borislav Mihov contributed to data acquisition. Andrew Grey, Mark Bolland and lan Reid contributed to data interpretation. Mark Bolland and Greg Gamble contributed to data analysis. Andrew Grey drafted the manuscript. All of the authors revised it critically for important intellectual content, approved the final version to be published and agreed to act as guarantors of the work.

Funding: Funding support was received from the Health Research Council of New Zealand. The funder had no role in the design and conduct of the study; the collection, management, analysis or interpretation of the data; or the preparation, review or approval of the manuscript.

Data sharing: Data are available to academic investigators from the authors upon request.

Accepted: Apr. 18, 2017

Correspondence to: Andrew Grey, a.grey@auckland.ac.nz 